\title{
LA FIGURA FEMENINA EN LA NARRATIVA UNIVERSAL
}

\author{
FEMALE FIGURE IN UNIVERSAL NARRATIVE
}

Nelly aliaga Murray ${ }^{1}$

\section{RESUMEN}

El presente artículo analiza la representación de la mujer en la literatura de todos los tiempos y de diversos lugares, centrándose en aquellos personajes femeninos de la narrativa universal, que han perdurado hasta nuestros días, y que atraviesan la ficción de diversos autores. Algunos de los personajes muestran una conducta de respeto a las normas y valores y en otros casos una conducta transgresora, de acuerdo a las características ideológicas, sociales y culturales del contexto. El artículo presenta la transformación de la mujer en la ficción.

\section{Palabras clave}

mujer, narrativa universal, representación, respeto a las normas, transgresora, transformación

\section{ABSTRACT}

This article examines the representation of women in literature of all times and from different places, focusing on those female characters in universal narrative that have survived until today, and going through the fiction of various authors. Some of the characters show respect for the norms and values and in some cases they show a transgressive behavior, according to the ideological, social, and cultural characteristics of the context. This article presents the transformation of women in fiction.

\section{Keywords}

women, universal narrative, representation, respect for rules, transgressive, transformation

\section{INTRODUCCIÓN}

El presente estudio se propone analizar la forma como se concibió a la mujer a través de algunas obras de la narrativa universal de todos los tiempos. Para el estudio, se han seleccionado aquellas obras donde destaca la figura femenina como arquetipo de la honestidad, virtud, liderazgo o en otros casos como transgresora de los valores de la época en la cual surgieron; observar, también cómo la mujer ha ido evolucionando, sentando precedentes en la ficción, a través de autores humanistas, hasta alcanzar su propia voz de narradora, por medio de la cual puede expresar su pensamiento.

Por otro lado, estamos de acuerdo con los teóricos que señalan que la literatura es el reflejo de la sociedad, en ese sentido, tanto en la literatura como en la realidad, antes del siglo XX, la mujer casi no tenía voz, y en escasas oportunidades fue protagonista de grandes hazañas, las cuales, estaban a cargo de hombres. Así se expresa Amaya Fernández con respecto a la mujer:

Docente Principal. Doctora y Magister en Educación con estudios concluidos de Maestría en Lengua y Literatura. Segunda Especialidad en Administración. Estudios de postgrado simple en Tokio y Madrid. Past especialista y Directora en la sede del Ministerio de Educación y consultora del mismo. Catedrática en Maestría. 
La concepción de la mujer, la coloca en un plano necesariamente dependiente del hombre, tanto por su supuesta debilidad moral, cuanto porque de ella depende aquel "honor" que es objeto toda la literatura escrita y oral de aquellos años y que recogen autores como Lope de Vega (Fuenteovejuna, Peribáñez y el comendador de Ocaña); Calderón de la Barca (El alcalde de Zalamea, El médico de la honra), Tirso de Molina (El burlador de Sevilla), etc. Al lado de ellos cabe destacar Fray Luis de León con La perfecta casada y Luis Vives con la Instrucción de la mujer cristiana, obras que tienen por objeto afirmar los consejos que debe escuchar la mujer para tener una vida honesta, la cual sería imposible si no estuviese bajo la tutela del varón. (Fernández et al.1997, p. 34).

El propósito era persuadir a la mujer de su condición inferior, para que aceptara sin ninguna duda la superioridad masculina, estos conceptos estaban tan arraigados que se transmitía de generación en generación, en el sentido que las mujeres debían vigilar su honra, mantener su castidad, lograr la humildad y la obediencia ciega al varón. Debía aceptar en silencio la infidelidad masculina y hasta los castigos físicos. Sólo la vida religiosa le permitía a la mujer tener una mejor educación y mayor respeto en la sociedad de los siglos XVI y XVII.

En varios estudios se afirma que la educación de la mujer se limitaba a actividades domésticas, y sobre todo a la práctica de las virtudes y el cuidado de la familia. En el mejor de los casos, podía instruirse en primeras letras, leer solo el catecismo, vida de santos y otros libros, previamente seleccionados por el padre. No podían leer novelas ni literatura profana, por el temor de que asimilase pensamientos pecaminosos. Debía formarse en la práctica de las labores femeninas: hilar, bordar, coser, cocinar. También se les enseñaba a tocar algún instrumento musical, y no podían entonar música mundana considerada como incitación al pecado.
Por otro lado, según Sigmund Freud, antes del siglo XX, la sociedad era represiva y mojigata en lo que respecta a la sexualidad, y sobre todo en lo que respecta a la educación de la mujer. Freud pretendía descubrir el alma humana. Estudió la conducta, las emociones, los pensamientos, las motivaciones, hasta los sueños.

Nos preguntamos, entonces ¿La mujer estuvo negada en la literatura?, ¿Es posible determinar la evolución del pensamiento femenino, a través de su conducta mostrada en las obras literarias? A fin de dar respuesta a estas interrogantes se ha decidido analizar directamente las mismas obras literarias, así, nuestro análisis, intenta recorrer grandes tramos de los periodos por los que ha atravesado la historia de la humanidad.

Observamos que la mujer siempre estuvo presente en la literatura, desde las primeras obras escritas, sin embargo, las obras no fueron escritas por mujeres, ellas no estaban preparadas para tal oficio. Solo les estaba permitido hacerse cargo del hogar, las labores domésticas y la maternidad, realmente no tenían autonomía, dependían del padre o el tutor y después del esposo. Se llegó a afirmar que tenían inteligencia inferior, Al respecto recordamos la frase atribuida a Aristóleles: "La mujer es un animal imperfecto", aunque Platón exigía mayor dignidad para la mujer, sin embargo, la frase permaneció arraigada por siglos en occidente, solo algunos filósofos o teóricos de la educación levantaron $\mathrm{su} \mathrm{voz}$ reclamando el derecho de aprender a leer y escribir para la mujer, al que solo podían acceder las mujeres de la nobleza o de la burguesía. Pese a todo, la historia de la literatura registra a Roswitha (932-975), religiosa benedictina alemana, entre las primeras mujeres que escribió literatura.

Con la novela del siglo XIX, autores como Sthendal, Flauber, Balzac, Tolstoi y la escritora Emily Bronts, presentan obras cuyas protagonistas son, algunas dulces, sumisas, honestas y dedicadas a su hogar y otras totalmente opuestas a las primeras. 
Por su parte, los movimientos feministas del siglo XX, también contribuyeron al cambio. En esta dirección la escritora Simone de Beauvoir lanza la frase (1949) que da inicio el movimiento feminista: "Una no nace mujer, sino que se hace mujer". Su reflexión concitó todo un panorama de cuestionamientos en el mundo intelectual, en especial para la interpretación de las igualdades y diferencias de los sexos.

Hasta nuestros días, la mujer no solo sigue presente en la literatura sino que ella también produce con su propia voz, analiza $e$ interpreta su condición y situación con ojos $y$ pensamiento femeninos. Las escritoras que han surgido desde mediados del siglo XX hasta nuestros días son innumerables, $y$ algunas hasta han sido galardonadas con el Premio Nóbel de Literatura. Pero, nuestro análisis de las obras literarias abarca épocas anteriores, constituyéndose en precedentes o percepciones que la sociedad tenía de la mujer, y son los escritores quienes van transmitiendo este pensamiento.

\section{ANÁLISIS DE LOS PERSONAJES}

PENÉLOPE, iniciamos nuestro estudio analizando este personaje, que aparece en La Odisea, obra clásica de la literatura universal, poema de género épico, compuesto por 24 cantos, de autoría del poeta griego Homero (aún está en discusión si aparece el siglo VII o el VIII a. C.). Penélope es la esposa de Ulises, llamado también Odiseo, rey de Itaca. Al partir Ulises para la guerra, le hace prometer a su esposa, que, si no consigue regresar a Troya, no se quedará sola, pues el niño necesita un padre; le pide que si no vuelve tome otro esposo, frente a lo cual ella responde que no dejará de esperarlo, pero si así lo desea, lo hará; sin embargo, ella sentencia que eso nunca sucederá. Lo cual nos da idea de su firmeza de carácter.

Penélope es el símbolo de la fidelidad conyugal, de la paciente espera y del amor incondicional al esposo. Esperó durante 20 años a su esposo que regresaba de la guerra de Troya, mientras era pretendida por algunos nobles, que buscaban hacerse de los bienes de Ulises. Frente a esta amenaza Penélope urde un plan para preservarse casta y defender la propiedad del esposo, mientras este regresa. Informa a sus pretendientes que aceptará la desaparición de Ulises y se casará nuevamente cuando termine de tejer el sudario para el ex rey Laertes (padre de Ulises). Ella teje de día y deshace el tejido de noche, con el propósito de mantener vivo el recuerdo de su esposo y no cumplir la promesa que hizo a los pretendientes. Felizmente regresa Ulises al hogar al lado de su fiel esposa y su hijo.

La Odisea traduce un concepto de mujer, propio de la estructura patriarcal de la sociedad preclásica en el contexto Egeo... Penélope representa la mujer romántica, que espera fielmente el regreso de su esposo. Ese modelo se ha ido leyendo como independencia, inteligencia, cuestionamiento del yo y del destino, a través de la construcción femenina, su propia historia materializada en el arte de tejer, es también metáfora de la soledad. (Piquer 2010, p.1).

En efecto, el personaje Penélope y su actividad de tejer, también ha tenido diversas interpretaciones a lo largo de los siglos, si durante la época romana es el símbolo del amor conyugal, el prototipo del ideal de mujer, después, con el cristianismo sería presentada como modelo de mujer prudente. Mientras que con Dante y durante el Humanismo Cristiano del Renacimiento, la imagen de Penélope vuelve a tener el significado de castidad, pudor y modelo de valores morales, así como el estereotipo de mujer laboriosa en el telar, que también se interpreta como soledad, aflicción o inacción. En el siglo XX, Joyce nos ofrece una versión muy moderna de la Odisea, con su obra Ulises, donde el personaje que interpreta a Penélope adopta otra personalidad diametralmente opuesta a la versión original.
SHEREZADE, llamada también SHEZNARDA, GERENARDA también SCHATHRAZADA es otro personaje que concitó nuestro interés literario. Dependiendo del idioma del traductor adopta diversas formas 
al escribir el nombre. Ella es protagonista e hilo conductor de Las mil y una noches, de autor anónimo. Se trata de una serie de cuentos orientales, especialmente árabes que contiene historias de amor, tragedias, leyendas religiosas, poemas y parodias. Los relatos surgen con la magia, uno tras otro o uno dentro de otro, desarrollando la técnica de las cajas chinas y una narrativa jerárquica. Las historias aparecieron en la época medieval (recopiladas en el siglo IX). Scheznarda simboliza la habilidad para crear y contar cuentos, considerada hoy de gran prestigio, además, ella es una estratega valiente, tiene confianza en sí misma y es solidaria con las jóvenes de su país, pues con su actitud espera salvar de la muerte a miles de mujeres y devolver la imagen de mujer honesta. En el relato se describe a Scheznarda como una mujer cultivada:

Poseía, sin embargo, el valor superior a su sexo y el ingenio y la perspicacia de que estaba dotada, Scheznarda, había leído muchos libros, y poseía una memoria prodigiosa. Había estudiado filosofía, historia y bellas artes; componía versos mucho mejor que los más celebrados poetas de su tiempo. Además, su belleza era perfecta y su corazón solo albergaba los sentimientos más nobles y generosos. (1960, p. 4).

Conocía las leyendas de los reyes antiguos y las historias de los pueblos pasados. Dicen que poseía también mil libros de crónicas referentes a los pueblos de las edades remotas, a los reyes de la antigüedad y sus poetas. Era muy elocuente y daba gusto oírla. (1960, p. 5).

Las mil y una noches se sintetiza en que el sultán Schariar fue traicionado por su esposa, por lo que decide vengarse en todas las mujeres, así decretó casarse cada día con una joven y después de la luna de miel, al amanecer, debían ser decapitadas. Scheznarda, la hija del visir, es la siguiente víctima (la 301), ella no se amilana y decide salvar a las doncellas; está segura que puede persuadir al sultán de no seguir eliminando a las jóvenes, con su más poderosa arma: el arte de narrar.
Así, Scheznarda se convierte en esposa del sultán y cada noche le narra un cuento, pero hábilmente deja el desenlace para la noche siguiente. El sultán se va conectando a la historia, interesado por conocer el final, de esta manera se posterga la sentencia de muerte. Ella es una fuente inagotable de historias por narrar, y el sultán vive fascinado por la inteligencia de esta mujer que durante mil y una noches, continuó contando cuentos.

MARCELA es uno de los personajes de El Ingenioso Hidalgo Don Quijote de la Mancha de Miguel de Cervantes Saavedra, novela cumbre de la literatura mundial, escrita en 1605, ambientada en España. En esta novela Cervantes humaniza a las mujeres y presenta varios tipos de mujeres, tanto colmadas de cualidades positivas, como con defectos, entre ellas: la sobrina, el ama, servidoras, sumisas e incultas; Teresa Panza, conservadora, realista, analfabeta; Maritornes, desinhibida sexualmente, torpe, inculta; Marcela, con un discurso feminista, independiente económicamente, libre y no necesita de un hombre; Dorotea, culta, aventurera, actriz; la Duquesa, noble, culta, aburrida de la vida; Dulcinea, la mujer ideal, Aldonza Lorenzo, la mujer fuerte; en fin, en la obra encontramos: cristianas, moriscas, pastoras, prostitutas, actrices y señoras.

El papel de la mujer en El Quijote representa un nuevo tipo de mujer del Siglo de Oro. Tenemos mujeres fuertes, independientes, que escogen cómo serán sus vidas. Estas mujeres no aceptan el papel sumiso de la mayoría de las mujeres en otras obras literarias de su tiempo. El Quijote muestra que las mujeres son individuos con pensamientos, ideas y sueños, en vez de sumisas, débiles y obedientes (Nelly 2012).

En Cervantes se observa otra perspectiva, de mayor respeto y apertura mental frente a la condición de la mujer de su época y a los ataques de otros autores hacia las mujeres, ellas solo pedían tener la misma educación y cultura que los hombres. Marcela se adelanta a la época. La historia de esta pastora es 
contada por hombres, en un contexto pastoril renacentista del amor cortés. Es un discurso que se escucha a través de la voz masculina, hasta que ella misma habla. Al respecto Zizek Slavoj, mencionado por Chauca, 2008, señala:

En el amor cortés ocurre una idealización de la mujer, hay un proceso de espiritualización de ella: la dama como un objeto sublime. Pero esta es una noción errónea, como Lacan destaca, en verdad, en el amor cortés la mujer pierde características concretas y es tratada como un ideal abstracto. El amor cortés cosifica a la mujer, nos presenta una mujer-cosa que funciona como un espejo donde los hombres proyectan su ideal narcisista (Chauca, 2008).

Marcela representa la voz femenina, que en una época cuando la mujer no podía expresarse, se atreve a autoafirmarse, a defenderse contra las críticas de la sociedad, que la condena sin escucharla, y a mostrarse como una persona libre. Por medio del discurso de Marcela, Cervantes expone las ideas humanistas renacentistas, según las cuales todo ser humano, hombre o mujer, posee espíritu y puede hacer uso del derecho de la libertad, de decidir su propia existencia, de amar a quien le parece y no a quien la sociedad le impone. Marcela eleva la voz para expresar su pensamiento:

La honra y las virtudes son adornos del alma, sin las cuales, el cuerpo, aunque lo sea, no debe parecer hermoso. Pues si la honestidad es una de las virtudes que al cuerpo y al alma más adornan y hermosean.

Yo nací libre, y para poder vivir libre escogí la soledad de los campos. Los árboles de estas montañas son mi compañía, las aguas claras de estos arroyos mis espejos, con los árboles y con las aguas comunico mis pensamientos y hermosura" (Cervantes 1967, p.101).

Marcela transgrede el discurso pastoril varonil con un lenguaje correcto, sin el uso de vulgarismos, hasta se aprecia cierta estilística; se afirma y adopta una posición activa con voz propia. Ejerce su derecho de argumentar, ella misma narra su drama demostrando su identidad y su soledad, pues abandonó al tío, rompiendo así las cadenas. Por lo cual don Quijote la admira y reitera en distintas ocasiones el valor de la libertad. Ella es transgresora porque es una mujer que no está sometida a la voluntad de hombre alguno y no está de acuerdo con el papel tradicional de la mujer, cuya máxima aspiración es casarse, no admite el control de otra persona. Con su actitud ella intenta cambia el ideal de mujer de aquella época.

BEATRIZ, personaje de la obra La Divina Comedia de Dante Alighieri. Poema Épico, escrito entre 1307 a 1321 . La obra tiene tres partes: Infierno, Purgatorio y Paraíso, dividida en cánticos, compuesta en tercetos. Se ordena de acuerdo al símbolo numérico 3 que evoca la Trinidad (Padre, Hijo y Espíritu Santo). Tiene tres personajes principales: Dante (el humanismo), Beatriz (la fe) y Virgilio (la razón). La estrofa cuenta con tres versos, cada cántico 33 cantos (el último 34), total 100 cantos. La rima corresponde a la Terza rima.

Beatriz Portinari, fue en la vida real el amor platónico de Dante y en la obra Beatriz está idealizada. Es transformada en mujer ángel, es decir, se convierte en un ideal cuya virtud y belleza la coloca en el nivel más elevado de la jerarquía, frente a una sociedad que consideraba inferior a la mujer. Sólo la virtud cristiana es capaz de elevar a la mujer al estado espiritual más alto.

Beatriz representa el amor humano y a la vez sagrado que inspira a Dante y lo guía al paraíso. Se aprecia, también una revaloración del pensamiento clásico, representado por Virgilio (pagano) y el mundo medieval, anunciando un nuevo movimiento el renacimiento, por tanto, la mujer, también debía ser revalorada, así, Beatriz después de muerta asciende al cielo, junto a la Virgen María, mientras Dante inicia un largo peregrinaje por el infierno, el purgatorio y el cielo. A la entrada del paraíso, Dante encuentra el espíritu luminoso de su amada, Beatriz se humaniza, hasta puede hablar con Dante y se convierte en 
su guía. Esto se puede interpretar como la conciliación entre el pensamiento medieval, que era tan rígido con las ideas renovadoras del Humanismo, donde la mujer es un ser real y no ideal, con todos sus defectos, errores, debilidades, pero, también con sus virtudes, como lo fue Beatriz en la vida real.

\section{LA CONSPIRACIÓN DE LA SAYA} Y MANTO (1561). En las Tradiciones Peruanas que analizaremos se evidencia el comportamiento de las mujeres frente a la rigidez y a la concepción que la sociedad tenía de ellas; sin embargo, los personajes femeninos, que hemos seleccionado, decidieron alejarse del modelo e ir labrando un nuevo esquema de pensamiento para la mujer del futuro. Recordemos, también que muchas de las tradiciones se inspiraron en casos reales que ocurrieron en el Perú de los virreyes y de la independencia, y que Palma con su inagotable gracia y picardía los recrea.

Como veremos en el siguiente relato, las limeñas no estaban reprimidas, así en la Tradición "La Conspiración de la Saya y Manto", el conde de Nieva, cuarto virrey del Perú dictó una ordenanza relacionada a la capa de los varones y el manto de las damas.

Nuestras abuelas, que eran más risueñas que las cosquillas, supieron hacer de la vida un carnaval constante. Las antiguas limeñas parecían fundidas en un mismo molde. Todas ellas eran de talle esbelto, brazo regordete, cintura de avispa, pie chiquirritico y ojos negros rasgados, habladoras como un libro que despedían más chispas que volcán en erupción (...) lucían protuberancias tan irresistibles $y$ apetitosas (...) Con saya y manto una limeña se parecía a otra como dos gotas de rocío. (Palma 1964, p. 165).

El arzobispo ordenó que aquella limeña que se presentase al templo o procesión en saya y manto ipso facto quedaba excomulgada, anathema. "Desde que Lima es Lima, mis lindas paisanas han sido aficionadas al bochinche... y siempre se han salido con la suya" (Palma 1964, p. 166). A las limeñas de aquel siglo no se les enseñaba mucho a escribir para que no escriban cartas, ni podían hacer protestas; pero las pícaras limeñas se ingeniaron para conspirar. En 24 horas se alborotaron y se unieron todas las mujeres, hasta la esposa del virrey.

La anarquía doméstica cundió. Las mujeres descuidaron el arreglo de la casa, el puchero estaba soso, los niños no encontraban madre que los envolviera y limpiara la moquita, los maridos iban con los calcetines rotos y la camisa más sucia que estropajo.

Cuando yo digo que las mujeres son capaces de sacar polvo debajo del agua y de contarle los pelos al diablo... Cuestión aplazada las autoridades cedieron y las limeñas cantaron victoria. Métanse ustedes con ellas y verán dónde les da el agua" (Palma 1964, p. 166).

En esta tradición se advierte hasta dónde pueden ser capaces de llegar las mujeres cuando les tocan sus intereses, y la moda siempre fue asunto de mujeres, pero lo que más les afectó es que estaba en peligro el ejercicio de su libertad. Ellas aprendieron a presionar de manera inteligente y a permanecer unidas hasta lograr la victoria. El relato deja entrever la realización de la primera huelga de brazos caídos llevada a cabo por las limeñas.

UNA MOZA DE ROMPE Y RAJA (1822).

La causa de la independencia corría el peligro de fracasar, entre otros motivos porque los realistas tenían en su poder Pasco y Potosí, y la casa de Moneda no tenía barras de plata para acuñar monedas. A alguien se le ocurrió imprimir papel moneda. El pueblo no lo aceptaba, entonces se emitió un bando amenazador a quien no lo acepte. Así se expresa Palma: "Más desvergonzada (...) era una hembra, de las de navaja en la liga y pata de gallo en la cintura, conocida en el pueblo de Lima con el apodo de la Lunareja. (...) dice un refrán: Mujer lunareja, mala hasta vieja". (Palma 1964, p. 969)

La Lunareja tenía una tienducha de zapatos en la calle Judíos. La mujer se negaba a aceptar los papelitos o billetes; por su boca se deslizaban sapos, culebras y demás alimañas: "Miren, miren al ladronazo Ñó San Martín... 
quiere llevarse la plata y dejarnos cartoncitos imprentados..." (Palma 1964, p. 970).

Las personas descontentas aplaudían las majaderías de la Lunareja. La procaz zapatera fue tomada prisionera y colocada en un tabladillo en la Plaza Mayor, donde la raparon. Por momentos pedía clemencia y otros daba arengas, fue expuesta a la vergüenza pública y desde entonces nadie se resistía a recibir papel moneda. Tiempo después, Gertrudis la Lunareja se unió a los realistas con Rodil. Fue una inconsciente más que se unió a la caballería realista y que cometieron excesos. La Lunareja murió, el mismo día que se firmó la capitulación del Callao. Gritando "iViva el rey!”.

Como se puede apreciar este es un personaje peculiar, se trataba de una recia mujer que tenía una confusión en sus convicciones políticas. Es poco inteligente, pero destaca por su decisión de abrasar apasionadamente una causa, aunque su escasa formación no le permitía ver con claridad su equivocación. Demostró ser poco hábil en la defensa de sus ideales, ella murió con la convicción que lo mejor para el Perú era continuar siendo una colonia de España.

\section{ROSA CAMPUSANO "La Protectora" y MANUELA SÁENZ "la Libertadora"} (1821-1824) protagonistas de una de las Tradiciones Peruanas de Ricardo Palma, relato perteneciente a la etapa del Perú independiente. El narrador manifiesta que la favorita de San Martín (Rosa Campusano) y la favorita de Bolívar (Manuela Sáenz) eran física y moralmente dos tipos contrapuestos.

En la Campusano vi a la mujer con toda las delicadeza de sentimientos y debilidades propias de su sexo. En el corazón de Rosa había un depósito de lágrimas y de afectos tiernos, y Dios le concedió hasta el goce de la maternidad, que negó a la Sáenz. Doña Manuela era una equivocación de la naturaleza, que en formas esculturalmente femeninas encarnó un espíritu y aspiraciones varoniles. No sabía llorar, sino encolerizarse como los hombres, de carácter duro. La Protectora amaba el hogar, y la Libertadora se encontraba como en su centro en medio de la turbulencia de los cuarteles y del campamento.

La primera pasea en calesa, la segunda a caballo y con pantalones bombachos. La Sáenz renunció a su sexo, mientras que la Campusano se enorgullecía de ser mujer. La primera educada por monjas en la austeridad de un convento, la segunda pasó su infancia en medio de la agitación social. La Campusano perfumaba su pañuelo con los más exquisitos extractos ingleses; la otra usaba la hombruna agua de verbena. Hasta en los gustos literarios había completa oposición. (Palma 1964, p. 962).

Finaliza la tradición con dos frases lapidarias: "La Campusano fue la mujermujer; la Sáenz fue la mujer-hombre". (Palma 1964, p. 963).

Esta tradición ilustra la influencia del romanticismo del ideal femenino: todo candor, delicadeza, belleza y sentimiento, y el concepto de mujer que se le atribuía ternura, reservándose para el hombre la fuerza y dureza de carácter. El hecho de comparar a ambos personajes a la luz de influencias románticas deja mal parada a Manuelita Sáenz, dejando entrever la idea que ella se sentía mejor asumiendo la conducta y rol masculinos de la época. Consideramos que Manuelita se adelantó a la época, pues hoy la mujer en capaz de emprender grandes empresas, asumir cargos directivos de alto nivel y hasta usar pantalones, sin perder su esencia femenina.

MARGARITA GAUTIER, personaje de La dama de las camelias, novela escrita por Alejandro Dumas (hijo) y publicada en 1848. La obra se inspira en un romance que tuvo Alejandro con Marie Duplessis, joven cortesana parisina, quien mantuvo relaciones con personajes importantes de la vida social. La novela se ubica dentro del movimiento literario del Realismo, y se encuentra bajo el influjo del naturalismo. Entre los temas se pueden encontrar los prejuicios de la sociedad de esa época frente 
a la conducta de la protagonista Margarita Gautier, la abnegación y la prostitución. Está escrita en un lenguaje sencillo $y$ consta de veintisiete capítulos sin títulos.

La protagonista, es una cortesana, hermosa, joven y enfermiza. Nació en el campo, pero abandonó a su familia para vivir en París, aquí su vida es licenciosa y sus gastos son excesivos. Tiene siempre un ramo de camelias junto a ella; en la obra se presenta como una mujer enamorada de Armando Duval, por su amor es capaz de grandes sacrificios, como vivir sencillamente en el campo con él, o desaparecer de la vida del enamorado para que este sea feliz. Margarita es despreciada por la sociedad, ella es una de los seres excluidos, no se le concibe en un papel de esposa o madre, tampoco se respeta sus sentimientos.

Su último acto de sacrificio es regresar a su vida licenciosa, a fin de acelerar su avanzada enfermedad, sufría de tisis, está cansada de la incomprensión. Margarita, demuestra su confianza y sacrificio por amor a Armando, con el siguiente discurso:

En una relación como la nuestra, si la mujer conserva un poco de dignidad, debe imponerse todos los sacrificios posibles, antes que pedir dinero a su amante y de dar visos de banalidad a su amor. Tú me amas, sí, segura estoy de ello, pero no sabes lo frágil que es el hilo que sujeta al corazón el amor que inspiran las mujeres de mi condición... Todo lo que te pido es que me ames, y tú me querrás lo mismo sin caballos, sin cachemiras y sin diamantes. Dumas, 1988, p.167.

EMMA, protagonista de la novela Madame Bovary, escrita por Gustavo Flaubert y publicada en París en 1857. La obra se ubica en el Romanticismo tardío y orígenes del Realismo (mitad del siglo XIX). Trata de una mujer casada y católica, que no se emociona con la maternidad, no encuentra sentido al matrimonio, lo encuentra aburrido, monótono, quiere vivir con los lujos de las clases altas, cuando ella pertenece a la clase media, por ello contrae deudas para comprar cosas superfluas.
En este sentido, Emma representa a la mujer insatisfecha y consumista, también contribuye a ello su escasa preparación para hacer frente a las obligaciones que se le impone a la mujer de ese siglo. La novela refleja fielmente, a manera de un retrato, el pensamiento de la sociedad.

En esta época la mujer debía reprimir sus sentimientos y Emma solo encuentra satisfacción cuando lee novelas románticas, que la conducen a estados febriles de ensoñación, ansiando otra vida y otro matrimonio. Por eso, ella se transforma cuando conoce a un joven estudiante, por quien siente una inmensa pasión. Este joven se convierte en su amante y ambos sobrepasan los límites de la moral impuesta por la sociedad. Finalmente, por haber roto las normas de la educación y las buenas costumbres, por haber traicionado a su esposo, dejarlo en la pobreza y desatender a su hija, la única salida que encuentra es la muerte. Se suicida con un puñado de arsénico, al poco tiempo el esposo se entera de la traición, por unas cartas de su difunta esposa y también muere, a consecuencia del dolor que le causó el enterarse de la conducta extremadamente liberal de madame Bovary, su poco inteligente esposa.

MOLLY BLOOM, personaje de la novela moderna Ulises (1922) del Irlandés James Joyce. Considerada la obra más importante de habla inglesa del siglo XX. En la novela se advierte novedosas técnicas narrativas, que han sido capitalizadas por muchos narradores del siglo XX y del presente. Cuenta con una estructura en paralelo con el poema épico la Odisea de Homero, tanto en aspectos simbólicos como retóricos.

La obra presenta a Molly, esposa de Leopold Bloom, como una mujer sin inhibiciones, cuenta sus experiencias personales referidas a su esposo, a su hija, sus conocidos, hasta sus experiencias sexuales extramatrimoniales, ella está recostada en su lecho; mientras su esposo (emulando a Ulises de la Odisea), en pos de aventuras, recorre todo un día, (16 de junio de 1904) la ciudad de Dublin. Molly, la Penélope moderna, del siglo XX, representa simbólicamente a Penélope de la Odisea, recreada por Joyce, con diferencias 
bien marcadas. Los siglos transcurridos transformaron a Penélope. Observamos que en la ficción, de mujer fiel pasa a ser infiel; de recatada a una mujer sin inhibiciones (esta se evidencia en el monólogo interior del epílogo de la novela). Se aprecia una nueva actitud femenina frente a la vida; así, en ciertas descripciones, consideradas obscenas por algunos críticos (cuando recién se publicó la obra), se observa a Molly liberal en exceso, rompe con la idea de pensamiento femenino (candor y pureza); además, Molly menciona el ciclo menstrual, la leche materna, aunque, Sor Juana Inés de la Cruz (México 16511695) en su poema Primero Sueño, sutilmente se refiere a los fluidos corporales como la leche materna. Molly representa el cambio femenino, su relato de solo ocho oraciones sin signos de puntuación, en 49 páginas, imita la fluidez, la incoherencia, la libertad sin restricciones y la desinhibición propia del pensamiento. Molly es el ícono, en la ficción, de la mujer sin censura.

\section{CONCLUSIONES}

Si la literatura universal refleja la cultura de la sociedad de cada época, entonces algunos de los tipos de mujer analizados, presentan conductas que no responden a la época en la cual surgieron. Las obras analizadas muestran personajes femeninos que protagonizan acciones, exhibiendo conductas, que en su momento eran impropias para la época, algunos de estos personajes reflejan un cambio en el pensamiento femenino. La idea que prevalece en los personajes analizados es que la mujer, igual que el varón, es capaz de tomar decisiones temerarias y busca liberarse de la rigidez y los convencionalismos sociales.

No todos los personajes femeninos analizados se muestran transgresores de los códigos morales, o sociales, algunas mujeres se presentan como virtuosas.

Todas las obras analizadas en el presente artículo fueron escritas por varones (Las mil y una noches es anónima, por lo tanto, no se sabe si el autor fue hombre o mujer), sin embargo, ellos conocen la psicología femenina. Por otro lado, en la literatura clásica, la mujer no tiene casi voz, es con Cervantes que la voz femenina tiene un espacio, por lo menos en la ficción, Hasta que la voz de la mujer es sonora, lo cual indica presencia, superación, visibilidad y afirmación.

Penélope de la Odisea de Homero es modelo de la mujer en la antigüedad, es virtuosa, fiel e inactiva; Molly, la Penélope de la novela Ulises de Joyce es infiel, desinhibida y activa. 


\section{REFERENCIAS}

Alighieri, D. (2000) La Divina Comedia. Barcelona: El Comercio.

Bajtin, M. (1994) El método formal en los estudios literarios. Madrid: Alianza Editorial.

Calsamiglia, H. y Tusón, A. (1999) Las cosas del decir. Manual de análisis del discurso. Barcelona: Ariel, S. A.

Cervantes, M. (1967) El Ingenioso Hidalgo Don Quijote de la Mancha. Barcelona: Sopena.

Chauca, E. M. (2008) Espéculo. Revista de estudios literarios. Universidad Complutense de Madrid, España. El URL. Disponible en internet http://www.ucm.es/info/especulo/nume ro37/traquijo.html

Dumas, Alejandro. (1988). La Dama de las Camelias. Lima: Ed. Confianza.

Fernández, A., Guerra, M. y otras. (1997) La mujer en la conquista y la evangelización en el Perú (Lima, 1550 - 1650). Lima: Pontificia Universidad Católica del Perú y UNIFE.

Flaubert, G. (1983). Madame Bovary. España: Ed. Bruguera.

Huárag, E. (2004) Estructuras y Estrategias Narrativas en las Tradiciones Peruanas de Ricardo Palma. Lima: Ricardo Palma.

Homero (1981) Odisea. Madrid: Ed. Edaf.

Joyce, J. (2008) Ulises. Buenos Aires: Gradifco.

Lay Milka. (2001). La mujer en la Literatura. Tesis.www.abracecultura.com/.../uploaded LA\%20MUJER\%20EN\%20

Nelly, J. (2004). La voz de la mujer en El Quijote. Universidad de Alabama. www.bama.ua.edu/tatuana/numero1/lavoz.pdf

Palma, R. (1964) Tradiciones Peruanas. Madrid: Aguilar, $5^{\circ}$ ed.

Piquer, R (2013) Penélope y el tejido del tiempo. XVI Seminario de Arqueología Clásica. Madrid: Universidad Complutense de Madrid.

www.ucm.es/centros/cont/descargas/documentos12336.pdf

s/a Las Mil y una Noches(1960) Buenos Aires: Colección Las obras famosas. 